\title{
Establishing Individualized Goals in a Supported Education Intervention: Program Influences on Goal-Setting and Attainment
}

\author{
Mary Elizabeth Collins \\ Boston University \\ Carol T. Mowbray \\ University of Michigan \\ Deborah Bybee \\ Michigan State University
}

\begin{abstract}
Objectives: Support for goal-setting and attainment is a frequent component of social work interventions aimed at fostering client growth. This study investigated goal-setting and attainment in the Michigan Supported Education Research Project, an intervention that provides support for adults with psychiatric disabilities to engage in postsecondary education. Method: An experimental design with three conditions was used and data was collected at five time points. The sample included 397 adults. Results: Results indicate increased complexity of goal statements over time. Goals became more specific for those in the treatment conditions and for those who were high participants. Multivariate models found that selecting school as the most important goal was a significant factor in predicting later enrollment. Conclusions: Interventions can influence the goals that are set by individuals. Because of its importance to social work practice, researchers and practitioners should pay more explicit attention to goal-setting.
\end{abstract}

Goal-setting is ubiquitous in daily life and in social work practice. Goals are established in individual, family, and group practice in substantive areas as diverse as substance use, homelessness, delinquency, and others (Banyard \&

Authors' Note: This study was funded by the Community Support Branch of the Center for Mental Health Services, SAMHSA, through a grant to the Michigan Department of Mental Health (Grant No. HD5-SM47669). It represents a collaboration between schools of social work at the University of Michigan, Eastern Michigan University, Wayne State University, and the Detroit-Wayne County Community Mental Health Agency. Correspondence may be addressed to Mary Collins, School of Social Work, Boston University, 264 Bay State Road, Boston, MA 02215 or via the Internet using mcollins@bu.edu.

Research on Social Work Practice, Vol. 9 No. 4, July 1999 483-507

(c) 1999 Sage Publications, Inc. 
Graham-Bermann, 1995; Carey, 1996; Fraser, 1996; Schopler, Galinsky, \& Alicke, 1985). Speaking specifically about social group work, Schopler et al. (1985) stated that goals "represent the ends towards which service is aimed and give direction and meaning to the encounter between social group worker and clients" (p. 140). Moreover, efforts to support goal-setting and attainment are congruent with social work values of empowerment and selfdetermination by assisting individuals in identifying and clarifying their own goals and by providing support in attaining goals.

Despite the importance of goal-setting to social work, explicit study of goal-setting and its relationship to goal attainment has not received much emphasis. Although there are several references to goal-setting in the social work literature, there are a number of general limitations to this work: Attention to goals is fairly minimal and usually one piece of a larger intervention or study; most studies emphasize therapeutic or treatment goals related to an identified problem; and in most studies, the characteristics of the goals themselves remain unexamined.

In this article, we focus specifically and exclusively on goal-setting and attainment, we examine normative goals (primarily education and employment) rather than therapeutic goals, and we examine the characteristics of goals. We use the goal-setting theory of Locke and Latham (1990) to provide conceptual guidance to the study of goals among participants in the Michigan Supported Education Research Project (MSERP), a federally funded demonstration project designed to provide support for adults with mental illness to attend postsecondary college or vocational training. The program theory is based on the Choose-Get-Keep model of psychiatric rehabilitation and supported education (Sullivan, Nicolellis, Danley, \& MacDonald-Wilson, 1993), which emphasizes person-centered goals and focuses on participant process rather than on practitioner activity. Although higher education is often desired by individuals with psychiatric disabilities, they are frequently deterred from obtaining this goal for several reasons. Mental illness often strikes in late adolescence or early adulthood, an age at which postsecondary education is a common pursuit; stigmatizing attitudes on the part of educational personnel may have impeded individual efforts to overcome obstacles created by the mental illness; most campuses lack supportive services for students with psychiatric disabilities; and repeated attempts and failure to attain education may have negatively affected an individual's own feelings about his or her ability to attain this goal. Thus, an aim of the program was to empower participants to set and attain higher educational and vocational goals than those typically encouraged. The program also provided skill development aimed at building self-efficacy regarding school and work. Moreover, teaching and practice of skills related to goal-setting and attainment provided the concrete 
assistance needed to advance toward one's own goals. Earlier evaluations of the MSERP (Collins, Bybee, \& Mowbray, 1998), as well as other evaluations of supported education programs (Cook \& Solomon, 1993; Hoffman \& Mastrianni, 1993; Tutty, Belanger, \& Gregory, 1993; Unger, Anthony, Sciarappa, \& Rogers, 1991), have reported on a variety of outcomes. This article explicitly examines goal-setting and its relationship to the behavioral outcome of school enrollment.

Theory on goal-setting, specifically that developed by Locke and Latham (1990), has examined goal-setting activity in laboratory and work settings. In such environments, goal-setting has similar purposes: It is an important activity because it serves to direct attention and action by indicating what needs to be accomplished (Locke, Shaw, Saari, \& Latham, 1981), and goals influence performance by stimulating the development of task strategies (Earley \& Perry, 1987; Locke et al., 1981; Smith, Locke, \& Barry, 1990). Goal-setting research has found several characteristics of goals to be related to performance, particularly goal difficulty and goal specificity. Research has consistently found that performance increases linearly with goal difficulty (assuming that the individual is committed to the goal and possesses the requisite ability to achieve it) (Locke \& Latham, 1990) and that more specific goals lead to higher performance compared to vague goals (Locke et al., 1991). Thus, quantitative goals (e.g., increase by 10\%) or a specific task list are more effective at increasing performance than vague "do your best" type goals. Researchers have found that the ambiguity of vague goals leads people to anticipate satisfaction from every level of their own performance. Consequently, maximum effort is not expended in pursuit of the goal (Locke, 1996).

Locke (1996) also reports that goal commitment is a critical factor when goals are difficult and specific. The factors found to be related to commitment fall into two main categories: individual belief that the goal is important and individual belief that the goal is attainable (Locke, 1996). Regarding the belief that the goal is important, organizational research has examined the role of leadership in convincing workers that certain performance goals are important (Locke \& Latham, 1990). Peers, too, can influence goal commitment by conveying normative information, by persuasion, and by serving as role models (Earley \& Kanfer, 1985). Locke also notes that people have the capacity to commit themselves to goals. More intensive cognitive processing regarding goals has also been linked to successful goal attainment (Gollwitzer, Heckhausen, \& Ratajczak, 1990) as has agreeing publicly to strive for a goal (Hollenbeck, Williams, \& Klein, 1989).

An individual's belief that a goal is attainable is largely based on his or her sense of self-efficacy (Bandura, 1982, 1986). Locke (1996) notes that in 
organizational settings this can be facilitated by providing people with needed experience and training, by selecting people based on their skills and abilities, by providing verbal expressions of confidence, by giving people information regarding what task strategies to use, and through the use of role modeling. Belief that total success is possible is not required as long as the person believes that partial success or progress toward the goal is meaningful (Locke, 1996).

Most of the research on goal-setting has involved experiments conducted in universities or in organizational settings focusing on work performance. This specific theoretical framework has not been applied to social work practice or incorporated as a component of evaluation. Yet, given the importance of goal-setting in many interventions, goal-setting theory is useful for examining individual goal-setting and attainment. Although goals are central to social work practice, little research has been aimed at exploring how goals can be measured, whether they can appropriately be used as short-term outcome measures, and whether they might also be mediators of more long-term outcomes. Consequently, in this article, goal-setting theory is applied to an evaluation of a social work intervention, and several questions are addressed to determine if this measurement approach works: Can goals and changes in goals be measured in social work practice? Is the setting of goals (as opposed to their attainment) an important short-term outcome of interventions? Are goal-setting and certain characteristics of goals related to outcomes (attainment of goals)? The article answers these questions by reporting on findings related to goal-setting and attainment in an intervention program.

\section{METHODOLOGY}

\section{Description of Intervention}

The MSERP enrolled a total of 397 participants in four cohorts; they began participation in Winter 1994, Summer 1994, Fall 1994, and Winter 1995. Prior to the start of the intervention, all participants completed a baseline interview. Following this, each participant was invited to orientation, received an information packet and was randomly assigned to one of three conditions: classroom, group, or individual.

The classroom model and the group model were held on a community college campus. Meetings occurred twice a week for 2.5 -hour sessions throughout two 14-week semesters. The classroom model used an academic support curriculum adapted from that developed at the Boston University Center for Psychiatric Rehabilitation (Unger, Danley, Kohn, \& Hutchinson, 1987). The 
aim of the group model was to create a supportive learning environment in which members could explore career and educational options and make meaningful, individualized decisions about their future direction; an agenda (curriculum) that incorporated learning goals to be pursued by the group was crafted, and ongoing formative evaluation of the group in meeting their learning goals was conducted. The individual model was a control group; it involved no structured or scheduled intervention. Instead, students in the individual model were assigned a staff person, who, on request, was available to assist students to meet their own self-defined needs.

\section{Description of Participants}

Participants were recruited from the Detroit metropolitan area. Applicants were primarily recruited from the public mental health system; however, some were recruited from self-help programs, advocacy services, and by word of mouth. Over a period of 15 months, 480 individuals applied for the project. Eligibility criteria included the following: (a) psychiatric disability of at least 1 year duration, (b) high school diploma or GED obtained or near completion, (c) interest in pursuing postsecondary education, and (d) willingness to use mental health services, if needed, during participation. Only 20 applicants were found ineligible or were unable to be screened $(4.2 \%)$.

Of the 460 potential enrollees, 63 were not interviewed at baseline due to participant refusal $(n=46$ or $10 \%)$ or inability to locate $(n=17$ or $3.7 \%)$. The final study sample, therefore, was 397 . There was a slightly higher percentage of female than male participants (52\% vs. $48 \%$ ) and, consistent with the racial composition of the catchment area, most were non-White (61\% Black, $38 \%$ White, and $1 \%$ other). The average age was 36.9 , ranging from 17 to 75 years.

On average, participants had experienced mental illness for more than 14 years. The vast majority received social security disability income (SSDI) or supplemental security income (SSI). From scores on the Personality Assessment Inventory (PAI) (Morey, 1991) administered at baseline, those enrolled in MSERP scored, on average, at least one standard deviation above the nonclinical normative means on six PAI subscales (anxiety, anxiety-related, borderline, depression, paranoia, and schizophrenia) with elevated scores on the remaining four subscales. Primary diagnosis was available for 240 subjects $(60.5 \%)$ from the management information system (MIS) of the Community Mental Health Board. Of these, $68 \%$ has a primary diagnosis of schizophrenia and related disorders, $25 \%$ were diagnosed with an affective disorder, and $8 \%$ with an anxiety or other unspecified disorder. 
About one fourth had only graduated from high school and one fourth had not; nearly half had some post-high school education. Most participants lived with family or in supervised settings; about one fifth lived alone and one tenth with friends. In terms of geographic distribution, participants resided in Detroit as well as the outlying areas of Wayne County; the proportion of MSERP participants by catchment area generally resembled that of the Community Mental Health Board's overall clientele.

\section{Research Design and Procedures}

The experiment involved random assignment of participants to one of the three conditions described above. The classroom and group conditions were considered active conditions because program staff actively delivered services at structured times throughout the two-semester intervention; the individual condition served as a control group because it involved no specific intervention although staff could be called on to assist students who asked for help. Data were collected at five time points: baseline (prior to enrollment), midway through the intervention (end of first term), graduation from the intervention (end of second term), 6-month follow-up, and 12-month follow-up. Data were collected by trained interviewers who conducted inperson interviews lasting approximately 1 hour. Interviews were conducted in the respondent's home whenever possible.

The interviews collected information in several main areas: demographics (race/ethnicity, age, gender, marital status, and income); school, work, and psychiatric history; social adjustment and support; symptomatology; and self-perceptions. Social adjustment was measured by the Social Adjustment Scale (Weissman \& Bothwell, 1976), which assessed individuals' social adjustment in the domains of family, financial, interpersonal, and housework. Support was measured by three items asking about encouragement from family and mental health professionals for work and education. Participants' social networks were assessed by asking respondents to name and describe individuals they would turn to for various forms of social support. Symptomatology was measured by the Symptom Checklist-10 (SCL-10): 10 items for the Brief Symptom Inventory (Derogatis \& Melisaratos, 1983), which correlate most highly with the total score (Cronbach's $\alpha=.87$ ). School selfefficacy (developed for this intervention) consisted of 10 statements representing behaviors important in an educational setting (e.g., passing tests in college and concentrating in class) for which participants rate the ease of their performing on a scale of 1 (very easy) to 6 (very difficult) $(\alpha=.89$ ).

Program attendance data in the classroom and group conditions were recorded by the staff; for the individual model, each contact the participant 
had with staff was recorded. Three levels of participation were defined: none, moderate, and high. In the class and group conditions, moderate participation was defined as having attended less than 20 sessions; high participation was defined as attending 20 or more sessions. In the individual condition, high participation was defined as 120 minutes or more of contact occurring over at least two contacts; moderate participation was some contact but less than that defined in high participation.

Questions about goals were asked following closed-ended questions regarding school and work history. The goals themselves and resources to accomplish the goals were asked in an open-ended format: "What educational or job related goals do you have that are important to you and that you will be working to accomplish over the next 6 months?" Other questions asked respondents to identify which goal was most important, what resources they felt they needed to accomplish the goal, who they would go to for help in achieving the goal, and how they rated their chances for accomplishing their goal on a scale of 1 to $4(1=$ definitely won't accomplish, $4=$ definitely will accomplish). Interviewers were instructed to probe for three goals and to encourage the respondent to state goals that were relevant to school and work and that were feasible to accomplish within 6 months.

\section{Coding Procedures}

Goal statements were coded on three dimensions: goal type, specificity, and status. Goal type was of interest to determine the extent to which students selected school-related goals versus other goal types. Goal specificity was of interest because of the consistent relationship between goal specificity and goal attainment found in the literature. Goal status was of interest as an indicator of the progression and completion of goals.

Six goal types were derived from the statements and were coded: school (college oriented), vocational school/training (postsecondary technical training), job (paid employment), school preparation (MSERP, GED, and subject tutoring), job preparation (job search and application), and personal (not educationally/vocationally focused). Four levels of specificity (none [no goals], low, moderate, and high) were developed; the number of details articulated defined the level of specificity. For example, "enroll in college" would be coded low; "take a course in accounting" would be coded moderate; and "take an accounting course at Wayne County Community College" would be coded high. Also, five levels of status (none [no goals], choose, begin, maintain, and complete) were developed. The levels of status were based on the Choose-Get-Keep model of supported education, where the goal of choosing involves participants' selection of an appropriate education/training site, the 
goal of getting is to secure admission, and the goal of keeping is to sustain enrollment, student success, and satisfaction (Anthony, Cohen, \& Danley, 1988; Sullivan et al., 1993). An additional category, complete, was added in our coding scheme, and the labels of some others were changed to more adequately reflect the content of responses. For example, "decide where to go to school" would be coded choose; "enroll in college" would be coded begin; "continue taking classes" would be coded maintain; and "get an A in the class" would be coded complete.

Resources to accomplish goals were coded based on categories developed after review of responses. The resource responses were coded into one of eight categories: financial, transportation, other concrete (e.g., clothing and school supplies), support/encouragement, internal action (actions the individual needs to take), internal health/attitude (mental/physical health and psychological attitude), external (e.g., classes offered at right time), and other.

After the coding scheme was developed, a research assistant with undergraduate training in social work, was trained on the coding scheme (definitions, examples, etc.) and a sample of 30 responses was selected for practice coding. Following this, a sample of 50 responses was selected to establish the reliability of the coding scheme. The initial level of Cohen's kappa was sufficient (ranging from .64 to .91) and the research assistant continued coding. A random sample of $10 \%$ of responses was coded by a second coder to ensure a high level of agreement was maintained throughout. Final kappas for the three goal type codes ranged from .67 to .81 , for the three status codes from .67 to .81 , for the three specificity codes from .57 to .91 , and for the two resources from .64 to .69 .

\section{Analysis}

Analysis focused on three areas to answer the questions outlined above. First, analysis described the goal characteristics of type, specificity, and status, and the associations among them. This was done to develop a descriptive picture of the goals and their attributes at baseline and their progression throughout the course of the intervention to address whether goals could be validly measured. Second, analyses examined goal-setting as a program outcome; that is, the influence of condition and participation on goals and changes in goals over time. It was hypothesized that goals would increase in specificity and status over time. Finally, analyses examined goals as predictors of later, behavioral outcomes. It was hypothesized that setting goals at baseline would relate to eventual college or training enrollments. Most of the analyses reported here examined the goal (and its attributes) that was identified 
by the respondent as being the most important (of the possible three goals named). Analyses in which this is not the case are noted below. A variety of statistical techniques were used including descriptive frequencies, chisquare analysis, analysis of covariance, and logistic regression.

\section{RESULTS}

\section{Descriptive Results}

At baseline, the majority of respondents (38\%) reported school to be their most important goal. Twenty-three percent reported school preparation to be the most important goal, followed by job (16\%), personal/other (8\%), vocational training $(5 \%)$, and job preparation $(2 \%)$. Seven percent provided no goals or didn't know. In terms of specificity, most (42\%) of the goals were of moderate specificity, followed by low specificity (37\%), then high specificity (7\%). Fifteen percent had either personal goals or did not state goals and therefore were not coded for specificity. In terms of goal status, most $(60 \%)$ aimed to begin goals, $17 \%$ aimed to complete goals, $6 \%$ aimed to choose goals, and 3\% aimed to maintain current goals. Again, the $15 \%$ with either personal goals or no stated goals could not be coded for goal status. Finally, regarding the resources needed to accomplish goals, most (30\%) described internal actions they needed to undertake to accomplish their goals. Many (21\%) said they did not need anything to accomplish their goals. Other responses included money (19\%), support (14\%), transportation (7\%), better individual attitude or health (6\%), and other (4\%).

Associations among goal characteristics. Patterns among goal characteristics at different time points were analyzed through a series of cross tabulations: goal type by goal type, goal type by specificity, and goal type by status at each of the five time points. Because several cells had few or no cases, goal type was recoded into five categories: don't know/personal, school, school prep, job, and vocational training/job prep.

Analysis of these recoded goals is presented in Table 1. In general, the associations between goal type at the different time points reflect some stability of goals (many goal types are maintained). Consistent with an educational intervention, large percentages of individuals have school goals at each time point. Among those stating school prep goals at baseline, the percentages decline at follow-up as individuals completed school prep activities. There is also a slight decline in school goals by 12 months. Job-related goals remain stable across time, and there are minor fluctuations (4\% to $13 \%$ ) in 
TABLE 1: Goal Type at Baseline by Goal Type at Midterm, Graduation, 6-, and 12-Month Follow-Up

\begin{tabular}{|c|c|c|c|c|}
\hline $\begin{array}{l}\text { Most Important Goal } \\
\text { at Baseline }\end{array}$ & $\begin{array}{l}\text { Most Important Goal } \\
\text { at Midterm }\end{array}$ & $\begin{array}{c}\text { Most Important Goal } \\
\text { at Graduation }\end{array}$ & $\begin{array}{c}\text { Most Important Goal } \\
\text { at } 6 \text { Months }\end{array}$ & $\begin{array}{c}\text { Most Important Goal } \\
\text { at } 12 \text { Months }\end{array}$ \\
\hline \multirow[t]{6}{*}{ Don't know(DK)/personal } & $(n=44)$ & $(n=42)$ & $(n=40)$ & $(n=41)$ \\
\hline & $11 \%$ DK/personal & $19 \%$ DK/personal & $33 \%$ DK/personal & $29 \%$ DK/personal \\
\hline & $36 \%$ School & $45 \%$ School & $40 \%$ School & $32 \%$ School \\
\hline & $18 \%$ School prep & $5 \%$ School prep & $13 \%$ School prep & $12 \%$ School prep \\
\hline & $25 \%$ Job & $24 \%$ Job & $10 \%$ Job & $17 \%$ Job \\
\hline & $\begin{array}{l}9 \% \text { Vocational } \\
\text { training/job prep }\end{array}$ & $\begin{array}{l}7 \% \text { Vocational } \\
\text { training/job prep }\end{array}$ & $\begin{array}{l}5 \% \text { Vocational } \\
\text { training/job prep }\end{array}$ & $\begin{array}{l}10 \% \text { Vocational } \\
\text { training/job prep }\end{array}$ \\
\hline \multirow[t]{6}{*}{ School } & $(n=124)$ & $(n=113)$ & $(n=106)$ & $(n=105)$ \\
\hline & $9 \%$ DK/personal & $11 \%$ DK/personal & $14 \%$ DK/personal & $19 \%$ DK/personal \\
\hline & $51 \%$ School & $49 \%$ School & $43 \%$ School & $42 \%$ School \\
\hline & $15 \%$ School prep & $9 \%$ School prep & 9\% School prep & $5 \%$ School prep \\
\hline & $18 \%$ Job & $26 \%$ Job & $24 \%$ Job & $23 \%$ Job \\
\hline & $\begin{array}{l}8 \% \text { Vocational } \\
\text { training/job prep }\end{array}$ & $\begin{array}{l}6 \% \text { Vocational } \\
\text { training/job prep }\end{array}$ & $\begin{array}{l}11 \% \text { Vocational } \\
\text { training/job prep }\end{array}$ & $\begin{array}{l}11 \% \text { Vocational } \\
\text { training/job prep }\end{array}$ \\
\hline \multirow[t]{3}{*}{ School prep } & $(n=76)$ & $(n=65)$ & $(n=64)$ & $(n=59)$ \\
\hline & 8\% DK/personal & $17 \%$ DK/personal & $16 \%$ DK/personal & $19 \%$ DK/personal \\
\hline & $32 \%$ School & $23 \%$ School & $22 \%$ School & $25 \%$ School \\
\hline
\end{tabular}




\begin{tabular}{|c|c|c|c|c|}
\hline & $40 \%$ School prep & $40 \%$ School prep & $25 \%$ School prep & $25 \%$ School prep \\
\hline & $18 \%$ Job & $15 \%$ Job & $27 \%$ Job & $19 \%$ Job \\
\hline & $\begin{array}{l}3 \% \text { Vocational } \\
\text { training/job prep }\end{array}$ & $\begin{array}{l}5 \% \text { Vocational } \\
\text { training/job prep }\end{array}$ & $\begin{array}{l}11 \% \text { Vocational } \\
\text { training/job prep }\end{array}$ & $\begin{array}{l}12 \% \text { Vocational } \\
\text { training/job prep }\end{array}$ \\
\hline \multirow[t]{6}{*}{ Job } & $(n=44)$ & $(n=48)$ & $(n=33)$ & $(n=36)$ \\
\hline & $18 \%$ DK/personal & $25 \%$ DK/personal & $18 \%$ DK/personal & $22 \%$ DK/personal \\
\hline & $32 \%$ School & $27 \%$ School & $27 \%$ School & $28 \%$ School \\
\hline & $14 \%$ School prep & $4 \%$ School prep & $3 \%$ School prep & $0 \%$ School prep \\
\hline & $36 \%$ Job & $38 \%$ Job & $39 \%$ Job & $39 \%$ Job \\
\hline & $\begin{array}{l}0 \% \text { Vocational } \\
\text { training/job prep }\end{array}$ & $\begin{array}{l}6 \% \text { Vocational } \\
\text { training/job prep }\end{array}$ & $\begin{array}{l}12 \% \text { Vocational } \\
\text { training/job prep }\end{array}$ & $\begin{array}{l}11 \% \text { Vocational } \\
\text { training/job prep }\end{array}$ \\
\hline \multirow[t]{6}{*}{ Vocational training/job prep } & $(n=24)$ & $(n=24)$ & $(n=24)$ & $(n=20)$ \\
\hline & $13 \%$ DK/personal & $21 \%$ DK/personal & $25 \%$ DK/personal & $15 \%$ DK/personal \\
\hline & $29 \%$ School & $29 \%$ School & $25 \%$ School & $35 \%$ School \\
\hline & $13 \%$ School prep & $13 \%$ School prep & $8 \%$ School prep & $5 \%$ School prep \\
\hline & $38 \%$ Job & $25 \%$ Job & $38 \%$ Job & $35 \%$ Job \\
\hline & $\begin{array}{l}8 \% \text { Vocational } \\
\text { training/job prep }\end{array}$ & $\begin{array}{l}13 \% \text { Vocational } \\
\text { training/job prep }\end{array}$ & $\begin{array}{l}4 \% \text { Vocational } \\
\text { training/job prep }\end{array}$ & $\begin{array}{l}10 \% \text { Vocational } \\
\text { training/job prep }\end{array}$ \\
\hline Bowker $\chi^{2}$ & n.s. & $21.90^{*}$ & $31.55^{\star}$ & $21.34^{*}$ \\
\hline
\end{tabular}


vocational training/job prep goals. Bowker's extension of the McNemar chisquare (Bowker, 1948; Marascuilo \& McSweeney, 1977) was used to statistically examine whether the symmetrical cell probabilities were unequal (i.e., whether changes occurred from baseline to each of the four time points). Significant change was found at graduation $\left(\chi^{2}=21.90, p<.05\right)$, at 6 months $\left(\chi^{2}=31.55, p<.05\right)$, and at 12 months $\left(\chi^{2}=21.34, p<.05\right)$ but not at midterm.

Analyses next examined the association between the goal type and its specificity. This data is provided in Table 2 . At each time point, specificity was found to have an association with type of goal. Among those with school goals, most were of low specificity at baseline and midterm but the majority were of moderate specificity at graduation, 6 months, and 12 months. A similar pattern was found for job goals; the majority were of low specificity at baseline and midterm but the majority were of moderate specificity at graduation, 6 months, and 12 months. For vocational training/job preparation and school preparation goals, the majority were of moderate specificity throughout, with an increase in the percentages of goals that were highly specific at 6 months and 12 months. Later analyses examine whether goals become increasingly specific over time.

To examine status, goal type was cross-tabulated with status (choose, begin, maintain, and complete) at each time point. As shown in Table 3, at each time, the association is highly significant. At all time points, the status of school and job goals is most commonly begin. ${ }^{1}$ For school goals, the percentage with goals of beginning school decline, whereas those maintaining or completing generally rise over time. This suggests some progression during the course of the program whereby participants plan to enroll in school at baseline and having accomplished this, shift their goals at later time points to stay enrolled or complete school courses. For job goals, on the other hand, it is uncommon at any time point that participants aim to complete these goals. Aside from beginning a job, choosing (i.e., finding) a job and maintaining (i.e., holding onto or increasing hours/pay/status) are more reasonable responses. On the other hand, as the results confirm, for school prep and vocational training/job prep, completing the goal is not unrealistic. These responses typically reflected time-limited, specific training or other preparation activities (e.g., MSERP and GED training) that have a specific end point and can be completed within a short time period.

To summarize, although there is variability in goal type, specificity, and status, the descriptive data measuring these domains suggest expected patterns. For example, there is a large percentage of school and school preparation goals, as would be expected in an educationally related intervention. There is also a significant relationship between type of goal and its specificity; school and job goals tend to be less specific than vocational training and 
TABLE 2: Goal Type by Specificity ${ }^{\mathrm{a}}$ at Baseline, Midterm, Graduation, 6- and 12Month Follow-Up

\begin{tabular}{lccccc}
\hline Baseline & $\begin{array}{c}\text { Midterm } \\
(\mathrm{n}=337)\end{array}$ & $\begin{array}{c}\text { Graduation } \\
(\mathrm{n}=280)\end{array}$ & $\begin{array}{c}6 \text { Months } \\
(\mathrm{n}=218)\end{array}$ & $\begin{array}{c}12 \text { Months } \\
(\mathrm{n}=207)\end{array}$ \\
\hline School & $(n=152)$ & $(n=125)$ & $(n=109)$ & $(n=91)$ & $\begin{array}{c}(n=88) \\
\text { High }\end{array}$ \\
Moderate & $8 \%$ & $2 \%$ & $5 \%$ & $22 \%$ & $23 \%$ \\
Low & $32 \%$ & $46 \%$ & $60 \%$ & $47 \%$ & $44 \%$ \\
Vocational training/ & $60 \%$ & $52 \%$ & $36 \%$ & $31 \%$ & $33 \%$ \\
job prep & $(n=27)$ & $(n=18)$ & $(n=19)$ & $(n=26)$ & $(n=29)$ \\
High & $15 \%$ & $6 \%$ & $16 \%$ & $27 \%$ & $35 \%$ \\
Moderate & $52 \%$ & $72 \%$ & $79 \%$ & $54 \%$ & $48 \%$ \\
Low & $33 \%$ & $22 \%$ & $5 \%$ & $19 \%$ & $17 \%$ \\
Job & $(n=65)$ & $(n=72)$ & $(n=74)$ & $(n=68)$ & $(n=64)$ \\
High & $11 \%$ & $0 \%$ & $11 \%$ & $7 \%$ & $14 \%$ \\
Moderate & $40 \%$ & $47 \%$ & $61 \%$ & $49 \%$ & $56 \%$ \\
Low & $49 \%$ & $53 \%$ & $28 \%$ & $44 \%$ & $30 \%$ \\
School prep & $(n=93)$ & $(n=65)$ & $(n=43)$ & $(n=33)$ & $(n=26)$ \\
High & $4 \%$ & $3 \%$ & $0 \%$ & $12 \%$ & $8 \%$ \\
Moderate & $81 \%$ & $79 \%$ & $91 \%$ & $82 \%$ & $81 \%$ \\
Low & $15 \%$ & $19 \%$ & $9 \%$ & $6 \%$ & $12 \%$ \\
& $\chi^{2}=60.72$ & $\chi^{2}=28.17$ & $\chi^{2}=24.99$ & $\chi^{2}=25.01$ & $\chi^{2}=16.44$ \\
& $d f=6$ & $d f=6$ & $d f=6$ & $d f=6$ & $d f=6$ \\
& $p<.001$ & $p<.001$ & $p<.001$ & $p<.001$ & $p<.05$ \\
\hline
\end{tabular}

a. Does not include "don't know" or personal goal responses.

school prep goals, and between type of goal and its status; vocational training and school prep goals also had larger percentages planning to complete these goals than school and job goals. Furthermore, attrition analysis comparing those who completed the 12-month interview with those who did not found no significant differences in the type, specificity, or status of goals mentioned at baseline.

\section{Goal as Outcomes}

Several analyses were conducted to examine the influence of the intervention on goal-setting. These analyses examined condition and participation level effects on type, specificity, and status. 
TABLE 3: Goal Type by Status ${ }^{\mathrm{a}}$ at Baseline, Midterm, Graduation, 6-, and 12-Month Follow-Up

\begin{tabular}{lccccc}
\hline Baseline & Midterm & Graduation & 6 Months & 12 Months \\
$(\mathrm{n}=337)$ & $(\mathrm{n}=280)$ & $(\mathrm{n}=218)$ & $(\mathrm{n}=207)$ \\
\hline School & $(n=152)$ & $(n=125)$ & $(n=109)$ & $(n=91)$ & $(n=89)$ \\
Choose & $1 \%$ & $1 \%$ & $1 \%$ & $0 \%$ & $0 \%$ \\
Begin & $84 \%$ & $82 \%$ & $70 \%$ & $66 \%$ & $64 \%$ \\
Maintain & $3 \%$ & $5 \%$ & $16 \%$ & $15 \%$ & $12 \%$ \\
Complete & $12 \%$ & $12 \%$ & $14 \%$ & $19 \%$ & $24 \%$ \\
Job & $(n=65)$ & $(n=72)$ & $(n=74)$ & $(n=68)$ & $(n=63)$ \\
Choose & $19 \%$ & $13 \%$ & $11 \%$ & $10 \%$ & $13 \%$ \\
Begin & $74 \%$ & $64 \%$ & $77 \%$ & $72 \%$ & $62 \%$ \\
Maintain & $5 \%$ & $19 \%$ & $10 \%$ & $18 \%$ & $18 \%$ \\
Complete & $3 \%$ & $4 \%$ & $3 \%$ & $0 \%$ & $8 \%$ \\
School prep & $(n=93)$ & $(n=65)$ & $(n=43)$ & $(n=33)$ & $(n=26)$ \\
Choose & $5 \%$ & $0 \%$ & $5 \%$ & $0 \%$ & $0 \%$ \\
Begin & $46 \%$ & $28 \%$ & $21 \%$ & $27 \%$ & $31 \%$ \\
Maintain & $3 \%$ & $0 \%$ & $7 \%$ & $9 \%$ & $4 \%$ \\
Complete & $45 \%$ & $72 \%$ & $67 \%$ & $64 \%$ & $65 \%$ \\
Vocational training/ & & & & & $(n \%=29)$ \\
job prep & $(n=27)$ & $(n=18)$ & $(n=19)$ & $(n=26)$ & $(n=29)$ \\
Choose & $15 \%$ & $0 \%$ & $0 \%$ & $4 \%$ & $3 \%$ \\
Begin & $63 \%$ & $44 \%$ & $42 \%$ & $77 \%$ & $55 \%$ \\
Maintain & $4 \%$ & $6 \%$ & $0 \%$ & $4 \%$ & $7 \%$ \\
Complete & $19 \%$ & $50 \%$ & $58 \%$ & $15 \%$ & $35 \%$ \\
& $\chi^{2}=78.69$ & $\chi^{2}=141.98$ & $\chi^{2}=95.89$ & $\chi^{2}=71.48$ & $\chi^{2}=47.64$ \\
& $d f=9$ & $d f=9$ & $d f=9$ & $d f=9$ & $d f=9$ \\
& $p<.001$ & $p<.001$ & $p<.001$ & $p<.001$ & $p<.001$ \\
\hline
\end{tabular}

a. Does not include "don't know" or personal goal responses.

Goal type. There was a significant association of program participation level and goal type at 12 months $\left(\chi^{2}=21.08, p<.05\right)$. High participants most frequently stated school $(41 \%)$ and vocational school $(16 \%)$ goals. To a lesser extent, moderate and nonparticipants also stated school to be their most important goal (34\% and 29\%, respectively) and second most frequently stated a job-related goal ( $28 \%$ and $27 \%$ ). No condition effects were found.

Specificity. In this analysis, specificity was analyzed as a continuous, interval-level variable by averaging over the three possible goals on a scale of 
TABLE 4: Condition and Participation Effects on Specificity at 12 Months

\begin{tabular}{lcc}
\hline & $\begin{array}{c}\text { Baseline } \\
\text { Mean (Standard Deviation) }\end{array}$ & $\begin{array}{c}12 \text { Months } \\
\text { Mean (Standard Deviation) }\end{array}$ \\
\hline Condition & & \\
Class & $1.34(.86)$ & $1.74(.99)$ \\
Group & $1.39(.79)$ & $1.47(1.02)$ \\
$\quad$ Individual & $1.41(.84)$ & $1.39(.94)$ \\
Participation & & \\
None & $1.35(.79)$ & $1.33(1.01)$ \\
Moderate & $1.40(.88)$ & $1.58(.93)$ \\
High & $1.41(.80)$ & $1.77(1.01)$ \\
\hline
\end{tabular}

NOTE: Condition effect: $F=3.08(2,257), p<.05$. Participation effect: $F=3.39(2,257)$, $p<.05$.

0 to $3(0=$ no goal, $1=$ Low, $2=$ Moderate, $3=$ High $)$. Analysis of covariance (ANCOVA) was used with the baseline measure of specificity as the covariate. At 12-month follow-up, both condition, $F=3.08(2,257), p<.05$, and participation level, $F=3.39(2,257), p<.05$, effects were found. Planned comparisons using directional one-tailed tests found that the class was more specific than the individual condition $(t=1.78, p<.05)$, and the moderate $(t=$ $1.70, p<.05)$ and high $(t=1.68, p<.05)$ participators were more specific in their goal-setting than nonparticipants. The data are displayed in Table 4.

Optimal goal-setting. A composite variable was created to serve as an indicator of optimal goal-setting. This was a dichotomous variable in which individuals were coded 1 if: goal type = school, vocational school, or job; specificity $=$ moderate or high; and status $=$ maintain or complete. Others were coded 0 . Combined, this variable was an indicator of a higher level of goal-setting (more appropriate, more substantively difficult, more specific, and more advanced in terms of progression) than other combinations. The percentages on this variable increased at each time point: $7 \%$ at baseline, $10 \%$ at midterm, $14 \%$ at graduation, $15 \%$ at 6-month follow-up, and $20 \%$ at 12-month follow-up. McNemar chi-square, testing change from baseline to 12 months, was significant $(17.97, p<.001)$. Examined within condition, the McNemar chi-square test was significant for both the classroom $(p<.05)$ and group $(p<.01)$ conditions but not for the individual condition.

Resources for accomplishing goals. Descriptive data on the sources of help for obtaining goals is provided in Table 5. The percentages reporting 
TABLE 5: Sources of Help With Goals ${ }^{a}$

\begin{tabular}{|c|c|c|c|c|c|c|}
\hline & Baseline & Midterm & Graduation & $\begin{array}{c}6 \\
\text { Months }\end{array}$ & $\begin{array}{c}12 \\
\text { Months }\end{array}$ & $\begin{array}{c}\text { McNemar } \\
\chi^{2 \mathrm{~b}}\end{array}$ \\
\hline Family & $44 \%$ & $47 \%$ & $43 \%$ & $47 \%$ & $43 \%$ & 1.82 n.s. \\
\hline Friends & $39 \%$ & $44 \%$ & $44 \%$ & $39 \%$ & $44 \%$ & .63 n.s. \\
\hline $\begin{array}{l}\text { Mental health } \\
\text { professional }\end{array}$ & $73 \%$ & $71 \%$ & $69 \%$ & $59 \%$ & $60 \%$ & $9.14^{* *}$ \\
\hline $\begin{array}{l}\text { Michigan } \\
\text { Rehabilitative }\end{array}$ & & & & & & \\
\hline Services & $35 \%$ & $37 \%$ & $41 \%$ & $43 \%$ & $41 \%$ & $4.40^{\star}$ \\
\hline Self-help group & $25 \%$ & $27 \%$ & $21 \%$ & $21 \%$ & $17 \%$ & $7.45^{\star *}$ \\
\hline $\begin{array}{l}\text { Michigan Supported } \\
\text { Education Research } \\
\text { Project (MSERP) } \\
\text { participants }\end{array}$ & & $43 \%$ & $34 \%$ & $36 \%$ & $34 \%$ & $4.40^{*}$ \\
\hline MSERP staff & & $61 \%$ & $59 \%$ & $54 \%$ & $55 \%$ & $4.10^{*}$ \\
\hline
\end{tabular}

a. Because multiple responses were possible, column percentages will be greater than $100 \%$.

b. Test for change from baseline to 12 months.

${ }^{*} p<.05 .{ }^{* *} p<.01$.

family and friends remained fairly constant across time period. Percentages of both mental health professionals and self-help groups decrease. Percentages of MSERP participants and staff also decrease. This would be expected after the program ends. Finally, the percentage of those responding that they would seek help from vocational rehabilitative services increases, reflecting an intended effect of MSERP.

Belief that goals are attainable. Students' self-rating of their likelihood of accomplishing goals remained quite consistent at each time point (3.41 at baseline, 3.42 at midterm, 3.36 at graduation, 3.40 at 6 months, and 3.40 at 12 months). ANCOVA found no condition or participation effects.

To summarize, this set of analyses viewed goals as outcomes and examined whether there was change over time in goal characteristics and whether condition and program participation affected goal characteristics. Participation affected goal type at 12 months; high participants were more likely to state school and vocational school goals. Both condition and participation affected goal specificity at 12 months; classroom participants were most specific, followed by the group and the individual conditions; and high participants were most specific, followed by moderate and nonparticipants. There was also an increase over time in the percentages describing optimal goals, 
and this change over time was significant within the two active conditions. Data also found change over time in the resources for accomplishing goals but no change over time for beliefs that goals are attainable.

\section{Relationship of Goal-Setting to Behavioral Outcomes}

The final area of analysis focused on the relationship between goal-setting and behavioral outcomes (goal attainment) within the domain of schoolrelated goals. This involved three steps: examining the relationship of goal-setting to behavioral outcomes, determining other factors influencing behavioral outcomes, and developing a multivariate model to determine the independent contribution of goal-setting to behavioral outcomes (goal attainment). Analysis of the goal to be attained focused first on enrollment in school during the course of the intervention (at midterm or graduation) and secondly on school enrollment postintervention (6-month or 12-month follow-up).

Bivariate relationships with college enrollment during the program. A significant association was found between stating school to be one's most important goal at baseline and enrollment in school during the course of the intervention $\left(\chi^{2}=17.91, p<.0001\right)$. Also, optimal goal-setting (i.e., school, vocational school, or job goal, of moderate or high specificity, and of maintenance or completion status) was found to be related to enrollment in college. Thirty-three percent of those with optimal goals were enrolled versus $17 \%$ of those without optimal goals $\left(\chi^{2}=4.37, p<.05\right)$. Other significant bivariate relationships with college enrollment during the program included the following: cohort, parent's college history, student's level of educational attainment, student's recent enrollment in college, recent involvement with state vocational rehabilitative services, and participation level in MSERP. Examined with $t$ tests (comparing those enrolled with those not enrolled), the continuous variables that were found to be significant $(\text { at }<.10)^{2}$ included: age of first mental health problems, symptoms (BSI), number of times seen mental health provider, social adjustment scale, social support, mental health worker's encouragement for education, parent's encouragement for education, and school efficacy. Variables tested but found to be nonsignificant included: age, gender, ethnicity, income, paid employment at baseline, diagnosis, condition assignment, mental health worker's encouragement for work, quality of life, esteem, empowerment, and social adjustment.

Multivariate analysis predicting college enrollment during the program. All significant variables at the bivariate level, with little missing data, were 
TABLE 6: Logistic Regression Predicting College Enrollment at Midterm or Graduation $(N=305)$

\begin{tabular}{lcccc}
\hline & $\mathrm{b}$ & $\mathrm{SE}$ & $\mathrm{df}$ & exp(b) \\
\hline Symptomatology & -.63 & .24 & 1 & $.53^{* *}$ \\
Recent college enrollment & .90 & .45 & 1 & $2.46^{*}$ \\
$\begin{array}{l}\text { Involvement with } \\
\text { rehabilitative services }\end{array}$ & .83 & .38 & 1 & $2.29^{*}$ \\
Social support & .13 & .05 & 1 & $1.15^{*}$ \\
Program participation & & & 2 & .60 \\
$\quad$ Moderate & -.51 & .45 & 1 & $2.43^{*}$ \\
$\quad$ High & .89 & .40 & 1 & $3.74^{*}$ \\
School as most important goal & 1.32 & .35 & 1 & \\
Constant & -.89 & .64 & & \\
\hline
\end{tabular}

NOTE: Initial log likelihood $=278.567$; model log likelihood $=224.278$.

${ }^{*} p<.05 .{ }^{* *} p<.01$.

considered candidates for inclusion in a multivariate model. Significant variables were entered in four groups reflecting: functioning (BSI and age of first mental health problems), previous schooling (educational attainment at intake, college enrollment within the past year, and school efficacy), support (mental health worker's encouragement for education, parent's encouragement for education, total amount of social support, and involvement with state vocational rehabilitation services), and program variables (participation level, stated school most important goal at baseline, stated optimal goal at baseline, and program cohort). To achieve a parsimonious model, backward stepwise procedures were used within each set. Six variables were found to be significantly predictive of college enrollment during the course of the program: BSI (symptomatology), enrollment in college within the year prior to baseline, involvement with state vocational rehabilitation services, social support, high participation in the program, and stating school to be the most important goal.

One variable was found to decrease the likelihood of later enrollment; higher scores on the symptomatology scale decreased the odds of enrollment by about half. Recent enrollment in college was a strong predictor of later enrollment, increasing the odds by about 2.5 times. Two social support variables also increased the odds of later enrollment. Involvement with state vocational rehabilitative services more than doubled the odds of enrollment and higher scores on the social support scale also increased the odds of enrollment. Finally, two program-related variables were found to increase the odds. 
High participants had more than double the odds of enrollment compared to nonparticipants in the program. The strongest factor in the model was having stated school to be the most important goal at baseline; this was found to increase the odds of enrollment by more that 3.5 times. Full results of the logistic regression model are in Table 6 . Overall the model accurately predicted college enrollment status during the intervention for $86 \%$ of cases, $98 \%$ of those not enrolled, and $29 \%$ of those who were enrolled.

Multivariate analysis predicting college enrollment after the program. Similar procedures were used to determine predictors for enrollment after program completion (i.e., at 6 or 12 months). The sample size was decreased somewhat because this model required data at baseline, graduation, 6, and 12 months $(N=233)$. Examining data in three sets: baseline variables, graduation variables, and program variables (participation level, stating school as important goal, and optimal goal-setting), six variables were found to be significant predictors of postprogram college enrollment. The strongest predictors were earlier college enrollment during the supported education program (increasing the odds of postprogram enrollment by 6 times) and prior to the start of the program (increasing the odds of postprogram enrollment by 5.5 times). Also significant at the .05 level was empowerment at baseline (more than doubling the odds of enrollment) and optimal goal-setting at graduation (more than doubling the odds of enrollment). Finally, two baseline variables demonstrated marginal significance: mental health worker's encouragement for education and having stated school to be the most important goal at graduation, each of which more than doubled the odds of later enrollment. These results are reported in Table 7 . The model was accurate in predicting the postprogram enrollment status of $83 \%$ of the cases; $94 \%$ of those who were not enrolled and $47 \%$ of those who were enrolled.

\section{DISCUSSION AND CONCLUSIONS}

\section{Measurement of Goals}

Goal type and several characteristics of goals identified in the goal-setting literature (goal difficulty, specificity, commitment, and self-confidence) were measured and examined over time. Goal type was measured and treated as a nominal level variable. Consequently, the ability to analyze change in goal type was limited but could be done with special, nonparametric tests for examining symmetric contingency tables. These tests showed change in goals between baseline and all time points except midterm. Analysis of the 
TABLE 7: Logistic Regression Predicting College Enrollment at 6 or 12 months $(N=233)$

\begin{tabular}{|c|c|c|c|c|}
\hline & $b$ & SE & $\mathrm{df}$ & $\exp (\mathrm{b})$ \\
\hline Empowerment & .92 & .47 & 1 & $2.50^{* *}$ \\
\hline $\begin{array}{l}\text { Recent college enrollment } \\
\text { (before the program) }\end{array}$ & 1.71 & .53 & 1 & $5.55^{\star \star *}$ \\
\hline $\begin{array}{l}\text { College enrollment during } \\
\text { the program }\end{array}$ & 1.80 & .42 & 1 & $6.06^{\star \star \star *}$ \\
\hline $\begin{array}{l}\text { Mental health worker's } \\
\text { encouragement for education } \\
\text { (at graduation) }\end{array}$ & .26 & .14 & 1 & $1.30^{*}$ \\
\hline $\begin{array}{l}\text { School as most important } \\
\text { goal (at graduation) }\end{array}$ & .70 & .39 & 1 & $2.01^{*}$ \\
\hline $\begin{array}{l}\text { Optimal goal-setting } \\
\text { (at graduation) }\end{array}$ & 1.01 & .51 & 1 & $2.76^{\star *}$ \\
\hline Constant & -3.22 & 1.48 & 1 & \\
\hline
\end{tabular}

NOTE: Initial log likelihood $=254.66$; model log likelihood $=225.65$

${ }^{*} p<.10 .{ }^{* *} p<.05 .{ }^{* * *} p<.01 .{ }^{* * *} p<.001$.

changes showed a general stability in goals over time with a lessening of school prep and job prep over time.

Goal difficulty in this study was reflected in goal type. School, vocational school, and job goals are assumed to be more difficult than those of school prep and job prep. As noted, school prep and job prep declined over time, which we attribute to the relative ease of completing school prep and job prep goals. Indeed, it is consonant with the purpose of MSERP that individuals begin with realistic steps and move on to more difficult goals as these initial steps are accomplished. The slight decline in school-related goals we attribute to processes of goal clarification, also an important component of this program.

Goal difficulty was also reflected in goal status; in general, maintenance or completion of goals is assumed to be more difficult than choosing or beginning goals. For example, it is more difficult to maintain good grades or to complete a course than it is to decide what course to take or to enroll in a course. Our constructed variable of optimal goal-setting was used to capture the developmental nature of goal-setting and showed a significant increase over time within the active conditions.

Goal specificity was measured as a continuous variable, and consequently, parametric statistics could be used to examine change in specificity over time. An increase in goal specificity was found and is further evidence of 
the program's effect on goal clarification as well as on providing education on steps needed to attain goals. Thus "go to college" early in the intervention becomes "enroll in two psychology courses next semester at the community college" later in the intervention. As discussed in the literature review, such specificity decreases ambiguity surrounding the threshold that is needed for successful attainment and thus serves to focus efforts in a clear direction. The increase in specificity might also reflect program participants' increased knowledge and sophistication about appropriate options and the necessary steps to take.

Both goal commitment and confidence in ability to complete goals are more a measure of the individual than of the actual goal. Consequently, neither was a main focus of this study. Goal commitment was not directly measured; however, participation level might be viewed as a proxy for goal commitment (i.e., those individuals more committed to goal attainment are likely to participate in the program to a greater extent). Discussed below, a high level of participation was found to be associated with increased specificity of goals and was also a predictor of later enrollment in college. Regarding individuals' confidence in meeting their goals, only one item was used to assess this and it demonstrated virtually no change throughout the course of the intervention and follow-up period. Although this might indicate that no change took place, it might also indicate that a more sensitive measure is needed or that as is the case with self-esteem, confidence in goals is a relatively stable construct.

\section{Goals as Outcomes}

The discussion above has already indicated that change was observed over the course of the program and follow-up period on most of the characteristics of goals that were measured. In addition, on some measures there were also condition and participation effects.

Both condition and participation level influenced specificity of goalsetting. High participants tended to be more specific. The explanation for this is straightforward: Greater exposure to information and support can help to set and clarify goals. In regard to condition, those in the classroom condition were found to have more specific goals. This finding is consistent with both program theory and other identified outcomes. Previous analysis (Collins et al., 1998) found the classroom condition to be most effective at influencing feelings of school efficacy and empowerment, whereas the group was most successful at influencing participation level and program satisfaction. Although both models focus on providing support for education and developing skills to succeed in an educational environment, the emphasis of the group model is 
more informal and mutually supportive and the classroom model is structured like a classroom environment.

\section{Goal-Setting Influence on Goal Attainment}

Finally, the logistic regression analysis examining the attainment of one goal type (college enrollment) demonstrated fairly clearly that goal-setting is a key factor in goal attainment. Having school as the most important goal was significant in predicting college enrollment while in the program as well as college enrollment 6 to 12 months after program completion. Moreover, the effect of this variable was significant even when controlling for the strong effects of earlier involvement in college. Therefore, goal-setting appears to be a significant factor in later goal attainment.

\section{IMPLICATIONS FOR SOCIAL WORK PRACTICE AND RESEARCH}

Social workers are involved in numerous interventions that aim to encourage individual growth and development and to implicitly set goals. The results reported here suggest that goal-setting can be quantified on a variety of dimensions. Furthermore, measurements of goals can be used to indicate success in the program and also seem to function as interim steps (mediators) likely to lead to longer term goal attainment. These results have a number of implications for social work practice and research.

First, as third-party payers are increasingly interested in documenting outcomes, specification of goals and tracking goals over time might be a fruitful area for development of outcome indicators. Goal attainment scaling was developed 20 or more years ago by psychologists to measure individually based outcomes (Kiresuk \& Sherman, 1968). However, this approach proved to be too variable for reliable comparisons of progress across clients. The approach used in this analysis - quantifying goal type, specificity, status, and optimal goal attainment—could address the psychometric problems that goal attainment could not.

Second, in working with clients, the results imply that helping clients set discrete, short-term goals may be a practical way to better help them achieve longer term goals. That is, in this analysis, we found that goals at baseline are predictive of attainment at graduation and that goals at graduation are predictive of attainment at follow-up, but that goals at baseline do not predict the longer term follow-up results as well. The implication, 
consistent with the literature, is that goal-setting is most helpful when focused toward shorter term steps that are part of a larger goal rather than toward the larger goal itself.

A key implication for social work research is that goals and their characteristics can be measured in various ways and that these measures relate to other outcomes. Further research might examine additional characteristics of goals that were not measured here (e.g., time horizon, understanding of potential obstacles, degree to which a goal is socially valued, etc.). Research might also more explicitly examine the role of peers, therapists, group leaders, and significant others in facilitating goal-setting and change, as well as external, macro-level factors that facilitate or impede goal-setting and attainment (e.g., environmental barriers such as lack of financial resources, stigma, discrimination, etc.) In addition, individual characteristics such as commitment to goals and self-confidence in attaining goals might be examined in more detail. Finally, qualitative research might also examine in more depth the processes by which goals are established and met as well as changed or discarded. Related to this, further study might examine the meaning of goals to the individuals and the source from which the goals arise.

The study has limitations as well as strengths. Most notably, a focus on this particular population (adults with mental illness) and this particular intervention (the Michigan Supported Education Research Project) limits the applicability of the findings for other populations and programs. The study does suggest the use of measuring goals in an intervention, and consequently, we believe encourages the use of goal measurement for other populations and programs to determine whether similar results are found. A second limitation of the study is the somewhat restricted nature of the goals examined. Numerous other characteristics of goals can and should be explored. We have made some suggestions above as to other domains that might be included in future goal-related research. Finally, as the examination and measurement of goals is a fairly unexplored area of inquiry, an additional limitation of this research is its primarily exploratory rather than hypothesis-testing nature. Further research, however, can use the results reported here for generating specific hypotheses to be tested.

\section{NOTES}

1. This was also a default code for stated goals without specific status (e.g., "computer programmer" and "psychology classes") assuming that the goal statement reflected new activities the individual planned to undertake. 
2. Hosmer and Lemeshow (1989) suggest that at the model-building stage, variables with $p$ values as high as $<.25$ may be considered for inclusion. Because of the large number of variables in this study, the more conservative value of .10 was used.

\section{REFERENCES}

Anthony, W. A., Cohen, M. R., \& Danley, K. S. (1988). The psychiatric rehabilitation approach as applied to vocational rehabilitation. In J. A. Ciardiello \& M. D. Bell (Eds.), Vocational rehabilitation of persons with prolonged psychiatric disorders (pp. 59-80). Baltimore: Johns Hopkins University Press.

Bandura, A. (1982). Self-efficacy mechanism in human agency. American Psychologist, 37, 122-147.

Bandura, A. (1986). Social foundations of thought and action: A social cognitive view. Englewood Cliffs, NJ: Prentice Hall.

Banyard, V. L., \& Graham-Bermann, S. A. (1995). Building and empowerment policy paradigm: Self-reported strengths of homeless mothers. American Journal of Orthopsychiatry, 65(4), 479-491.

Bowker, A. H. (1948). A test for symmetry in contingency tables. Journal of the American Statistical Association, 43, 572-574.

Carey, K. B. (1996). Substance use reduction in the context of outpatient psychiatric treatment: A collaborative, motivational, harm reduction approach. Community Mental Health Journal, 32(3), 291-306.

Collins, M. E., Bybee, D., \& Mowbray, C. T. (1998). Effectiveness of supported education for individuals with psychiatric disabilities: Results from an experimental study. Community Mental Health Journal, 34(6), 595-613.

Cook, J. A., \& Solomon, M. L. (1993). The Community Scholar Program: An outcome study of supported education for students with severe mental illness. Psychosocial Rehabilitation Journal, 17(1), 83-97.

Derogatis, L., \& Melisaratos, N. (1983). The Brief Symptom Inventory: An introductory report. Psychological Medicine, 13, 595-605.

Earley, P. C., \& Kanfer, R. (1985). The influence of component participation and role models on goal acceptance, goal satisfaction and performance. Organizational Behavior and Human Decision Processes, 36, 378-390.

Earley, P. C., \& Perry, B. C. (1987). Work plan availability and performance: An assessment of task strategy priming on subsequent task completion. Organizational Behavior and Human Decision Processes, 39, 279-302.

Fraser, M. W. (1996). Cognitive problem solving and aggressive behavior among children. Families in Society, 77(1), 19-32.

Gollwitzer, P. M., Heckhausen, H., \& Ratajczak, K. (1990). From weighing to willing: Approaching a change decision through prior or postdecisional mentation. Organizational Behavior and Human Decision Processes, 45, 41-65.

Hoffman, F. L., \& Mastrianni, X. (1993). The role of supported education in the inpatient treatment of young adults: A two-site comparison. Psychosocial Rehabilitation Journal, 17(1), 109-119.

Hollenbeck, F. R., Williams, C. R., \& Klein, H. J. (1989). An empirical examination of the antecedents of commitment to difficult goals. Journal of Applied Psychology, 74, 18-23.

Hosmer, D. W., \& Lemeshow, S. (1989). Applied logistic regression. New York: John Wiley. 
Kiresuk, T. J., \& Sherman, K. E. (1968). Goal attainment scaling: A general method for evaluating comprehensive mental health programs. Community Mental Health Journal, 4, 443-453.

Locke, E. A. (1996). Motivation through conscious goal setting. Applied and Preventive Psychology, 5, 117-124.

Locke, E. A., \& Latham, G. P. (1990). A theory of goal setting and task performance. Englewood Cliffs, NJ: Prentice Hall.

Locke, E. A., Shaw, K. N., Saari, L. M., \& Latham, G. P. (1981). Goal setting and task performance: 1969-1980. Psychological Bulletin, 90, 125-152.

Marascuilo, L. A., \& McSweeney, M. (1977). Nonparametric and distribution-free methods for the social sciences. Pacific Grove, CA: Brooks/Cole.

Morey, L. C. (1991). Personality assessment inventory: Professional manual. Odessa, FL: Psychological Assessment Resources, Inc.

Schopler, J. H., Galinsky, M. J., \& Alicke, M. D. (1985). Goals in social group work practice: Formulation, implementation, and evaluation. In M. Sundel, P. Glasser, R. Sarri, \& R. Vinter (Eds.), Individual change through small groups (pp. 140-158). New York: Free Press.

Smith, K. G., Locke, E. A., \& Barry, D. (1990). Goal setting, planning and organizational performance: An experimental simulation. Organizational Behavior and Human Decision Processes, 46, 118-134.

Sullivan, A .P., Nicolellis, D. L., Danley, K. S., \& MacDonald-Wilson, K. (1993). Choose-Get-Keep: A psychiatric rehabilitation approach to supported education. Psychosocial Rehabilitation Journal, 17(1), 55-58.

Tutty, L., Belanger, J., \& Gregory, B. (1993). Redirection through education: An evaluation of a psychosocial rehabilitation program for psychiatrically disabled young adults. Psychosocial Rehabilitation Journal, 16(3), 9-25.

Unger, K. V., Anthony, W. A., Sciarappa, K., \& Rogers, E. S. (1991). A supported education program for young adults with long-term mental illness. Hospital and Community Psychiatry, 42(8), 838-842.

Unger, K. Danley, K., Kohn, L., \& Hutchinson, D. (1987). Rehabilitation through education: A university-based continuing education program for young adults with psychiatric disabilities on a university campus. Psychosocial Rehabilitation Journal, 10(3), 35-49.

Weissman, M. M., \& Bothwell, S. (1976). Assessment of social adjustment by patient selfreport. Archives of General Psychiatry, 33, 1111-1115. 